\title{
PRESENTACIÓN
}

\section{LA HIBRIDACIÓN GENÉRICA EN EL TEATRO DE LOPE DE VEGA}

\section{Marcella Trambaioli (Università del Piemonte Orientale, Vercelli)}

DOI: <https://doi.org/10.5565/rev/anuariolopedevega.452>

\begin{abstract}
$A$ todas luces, la mezcla, la contaminación, el matiz combinatorio, la hibridación de rasgos genéricos heterogéneos forman parte de la estética barroca en todas sus determinaciones artísticas y literarias. Desde luego, la comedia nueva, siendo ya de por sí «otro Minotauro de Pasife», según la acertada definición que Lope nos entrega en el Arte Nuevo (v. 176), resulta ser uno de los ámbitos privilegiados para realizar mezclas genéricas sorprendentes. Por eso, abordar el problema de la taxonomía en el teatro del Fénix implica, entre otras cosas, plantearse justamente la cuestión de la hibridación genérica que atañe a todas las fases de la producción dramática lopesca. No resulta baladí apuntar, al respecto, que la tendencia a la mezcla e «impureza» de la dramaturgia del madrileño mucho tiene que ver con su voluntad de desafiar y jugar continuamente con las expectativas del público.

Partiendo de las observaciones pioneras de Joan Oleza [1981], que el propio estudioso levantino ha profundizado posteriormente (Oleza 1994), Antonucci [2013] ha intentado sistematizar la cuestión de la contaminación entre géneros distintos centrando la atención sobre todo en la comedia palatina, cuya materia se imbrica muy a menudo con lo villano y/o lo pastoril, aun sin olvidar las piezas de ambientación urbana, las cuales en algunos casos presentan secuencias y personajes típicos de intrigas novelescas y de espacios exóticos.

También muy frecuente es la presencia de cuadros bucólicos aun en la comedia de ambientación urbana en todas las épocas de la producción lopesca, como índice de la cortesanización de este mismo subgénero teatral. Ejemplos acabados de esta tendencia serían obras como El acero de Madrid y La burgalesa de Lerma, entre otras.
\end{abstract}


La mezcla genérica implica asimismo la hibridación de personajes y de los códigos lingüísticos que los mismos emplean, conforme al cambiante estatuto social. Por ejemplo, la figura del jardinero fingido, que no es sino un noble que se disfraza para poder galantear a su amada, con el correspondiente rebajamiento momentáneo de su condición de galán, implica la inserción de secuencias villanescas tanto en la comedia palatina ( $E l$ soldado amante) como en la de ambiente urbano (Los ramilletes de Madrid). Análogamente la bandolera —que suele corresponder a una dama que ha perdido el honor y con ello su condición social— conlleva una contaminación genérica parecida. Pensemos tan solo en La serrana de la Vera.

Más aún: la hibridación de los subtipos teatrales determina imprevistas e inesperadas variaciones de los espacios dramáticos, e incluso el empleo de la métrica ofrece en algunos casos formas híbridas que andan parejas con la contaminación genérica, teniendo en cuenta que en la poesía no dramática lopesca ya se han rastreado ejemplos destacados, según ha puesto de relieve Yolanda Novo por ejemplo con respecto a la elegía.

Por supuesto, tratándose de Lope, no se puede pasar por alto un tipo de hibridación de su teatro muy peculiar, que corresponde a la contaminación entre discurso autobiográfico, dimensión panegírica y fabulación literaria. En íntima relación con este hecho, es preciso analizar desde el punto de vista de la hibridación el conjunto de cada Parte de comedias, para aclarar si en algunos casos la voluntad autorial pretende relacionar una clase determinada de contaminación genérica con los paratextos y los respectivos dedicatarios. Considerando que desde la Parte XIII Lope atribuye a cada pieza una dedicatoria con vistas a defender su preeminencia en la élite cultural de la época, a propósito de la Parte XVI d'Artois [2008], evidencia una estricta relación de raigambre cortesana entre arquitectura general, subgénero de las comedias seleccionadas y dedicatarios, y bajo esta misma luz cabría profundizar el estudio de otros corpora textuales.

Cierto es que el maremágnum del teatro de Lope ofrece un sinnúmero de combinaciones genéricas, es decir de comedias liminares y proteicas, que merecen la pena ser escudriñadas caso por caso, a sabiendas de que siempre saldrá a relucir algún ejemplo que difiere de todos los demás. Prueba de ello son los ensayos que se recogen en el presente monográfico del Anuario Lope de Vega. Texto, literatura, cultura, cuyas propuestas intentaré sintetizar a continuación.

Ante todo, cabe destacar que los primeros cuatro ensayos se centran en come- 
dias de la primera etapa del Fénix, en la que el juego combinatorio intergenérico resulta especialmente desarrollado y fructífero.

Delia Gavela, en «El espacio y los personajes villanescos en algunas comedias urbanas de Lope: tradición, hibridación y oportunismo dramático», dedica unas profundas y sugerentes reflexiones sobre el subtipo dramático más representativo de todas las fases de la extensa producción del Fénix en relación con lo campesino o rural, declinado tanto en clave rústica como pastoril, aislando un corpus significativo: La serrana de Tormes, La serrana de la Vera, Los embustes de Celauro, La villana de Getafe y Al pasar del arroyo. En estas piezas, todas tempranas salvo la última, espacios urbanos e incursiones exteriores se alternan e imbrican, creando intersecciones serias y jocosas, cada vez distintas, entre los polos dialécticos de la civilización y el primitivismo representados por los personajes correspondientes. En el juego combinatorio destacan algunos elementos reiterados, tales como el resorte de las identidades ocultas y el empleo del espacio rural como refugio para damas y caballeros en apuros; sin embargo, el contexto campesino, lejos de ser uniforme, varía en relación con factores distintos que lo acercan o bien a lo novelesco, o bien a lo folclórico, sin dejar de lado la necesidad de dignificar la clase social del villano acomodado que se impone en la pluma lopesca a partir de un momento dado con las comedias villanescas, Peribáñez (1605-1608) in primis.

Luciana Gentilli, en «Las Batuecas lopescas: cuando lo híbrido se hace espectáculo», tras reseñar el amplio abanico de rótulos utilizados por los críticos a la hora de clasificar Las Batuecas del duque de Alba, pieza compuesta entre 1594 y 1600, logra ilustrar con su tino habitual las muchas razones que hacen de ella «una obra ostensiblemente liminar, de difícil imbricación, proteica en géneros, temas, tipos, lugares y tiempos». El cruce constante entre los dos espacios dramáticos principales (es decir, la tierra salvaje de los batuecos y la corte albina, con sus respectivos moradores) produce las contaminaciones más llamativas, sin olvidar la relevante dimensión encomiástica, que apunta al subgénero de la comedia genealógica, atravesada por los ecos autobiográficos autoriales con la presencia del villano Belardo, así como el plano doctrinal y político que justifican, en el discurso oficial de la España coetánea, las gestas colonizadoras del imperio de los Austrias. El lenguaje refleja oportunamente la naturaleza híbrida e hibridatoria de la comedia, resultando polifónico.

Christophe Couderc, en «La disonancia genérica en la comedia palatina temprana. El ejemplo de Laura perseguida (1594)», fija su atención en una obra consi- 
derada, por lo general, palatina, pero que, a raíz de su peculiar mezcla tragicómica y de la muy variada procedencia de los materiales que la constituyen, adquiere matices genéricos ambiguos. En relación con los macrogéneros teatrales de ascendencia aristotélica, y los marcadores relativos, la pieza se podría tildar de «tragedia comicizada» 0 «comedia tragedizada». El propio tema de la acción, es decir la oposición entre el rey y el príncipe Oranteo por cuestiones matrimoniales, no es un asunto típico del género trágico por carecer del criterio de la elevación. Además, el carácter del monarca oscila entre la figura del rey terrible y la del rey risible. Finalmente, el papel de los actores implica un virtuosismo técnico especialmente acusado, que, junto con la estructura discontinua, permite acercar la obra a una partitura operística, siendo un destacado ejemplo temprano de teatro de la performance. Al fin y al cabo, Lope es el autor de la primera ópera en lengua castellana enteramente cantada: La selva sin amor.

La propuesta de Gaston Gilabert en «Lo sobrenatural y sus hibridaciones en el primer Lope de Vega: hacia un nuevo género dramático» resulta muy original y sugerente, abriendo una perspectiva inédita que estriba en la identificación de un macro-género sobrenatural que abarcaría todas aquellas comedias donde funcionan procedimientos relacionados con lo maravilloso, lo milagrero y la magia. En concreto, la categoría aislada por el autor atañe a la comedia hagiográfica, la pieza mitológica y la comedia de magia. En este último caso, el estudio de la hibridación permite trazar una línea dramatúrgica que une el teatro renacentista de magos a la comedia de tramoya de las postrimerías del siglo xviI y de la centuria siguiente. Los conocimientos musicales de Gilabert le permiten analizar con competencia técnica el empleo de las secuencias musicales que se relacionan con lo sobrenatural en los distintos subtipos dramáticos, identificando estrategias comunes que, por lo mismo, producen algunas de las contaminaciones y mezclas teatralmente más eficaces. $\mathrm{Al}$ respecto, una de las consideraciones más relevantes que podemos leer en este sugerente artículo, que analiza hasta setenta y cuatro comedias del primer Lope y asegura la predilección del poeta por la «impureza», afirma: «lo sobrenatural puede llegar a imponer una pauta escritural con independencia del signo religioso pagano o cristiano».

El artículo de Javier Rubiera, «Hibridez genérica y unidad artística en la comedia de santos: el proceso de hibridación en Lo fingido verdadero", analiza con finura y con acierto los problemas genéricos de una pieza que se remonta a una época del Lope maduro (c. 1608) y que ha hecho verter ya mucha tinta a los estudiosos a la hora 
de inscribirla en un género determinado. Según apunta el investigador, la comedia hagiográfica, que, de buenas a primeras, sería la categoría en que se suele enmarcar Lo fingido verdadero, es ya de por sí híbrida, por presentar elementos de distinta naturaleza. Por otra parte, su original escenificación del tópico del theatrum mundi hace de ella, sin falta, un hito de la metateatralidad aurisecular. Otros subtipos dramáticos implicados serían los de la «comedia metafísica», la «comedia de tiranos» y la «comedia de mártires». Por eso mismo, los críticos, a partir de Menéndez Pelayo, han considerado la pieza desequilibrada o mal estructurada. En realidad, tal como sugiere Luigi Giuliani (y remacha Rubiera), se trata de considerar que en la economía de la comedia funcionan, imbricándose y contaminándose entre sí, tres paradigmas genéricos: el del drama histórico, el de la comedia de capa y espada, y el de la comedia de santos, sin olvidar los rasgos de los demás subgéneros anteriormente identificados. En definitiva, Lo fingido verdadero «es una obra que integra numerosos elementos de naturaleza heterogénea y que explora a fondo los límites de la hibridez genérica mediante múltiples combinaciones», lo que constituye su excepcional originalidad.

Cierra el monográfico Irene Pacheco, con un artículo de corte preceptivo, titulado «Lo trágico y lo cómico mezclado con la teoría dramática del Romanticismo alemán», centrando su atención en la naturaleza híbrida del macrogénero que corresponde a la Comedia Nueva como «monstruo cómico» utilizando las lentes del Romanticismo alemán. En efecto, si hay una mirada cultural favorable al teatro barroco español en la Europa moderna, tras las evaluaciones negativas y condenatorias del siglo xvIII, es precisamente la óptica germana de autores como A.W. Schlegel, quienes lo consideran un modelo paradigmático para el drama romántico. La autora va espigando una serie relevante de pareceres críticos que, a partir de la primera mitad del siglo XviII, dan cuenta de la cambiante recepción de la comedia en relación con la infracción de las reglas de la poética aristotélica y la mezcla genérica. De hecho, los teóricos alemanes pasan de considerarla un error o imperfección artística a encarecerla como producto de libertad creadora y rasgo de modernidad.

Deseo rematar estas palabras prologales invitando a todo apasionado de Lope de Vega a leer con detenimiento e interés las contribuciones aquí reunidas, porque cada una representa una cantera de sugerencias y sutiles reflexiones que darán pie, sin falta, a ulteriores y necesarias profundizaciones en torno al hibridismo de la comedia lopesca, que sigue revelándose cada vez más como un fascinante calidoscopio o mecanismo dramático combinatorio sorprendente y sumamente proteico. 


\section{BIBLIOGRAFÍA}

Antonucci, Fausta, «Hibridación genérica en el teatro de Lope. Reflexiones al hilo de unas búsquedas en la base de datos ARTELOPE», Teatro de palabras, VII (2013), pp. 141-158.

D’ArToIs, Florence, «Tragedia, tragicomedia, comedia: ¿el género como patrón de composición de recepción de las Partes XVI y XX de Lope de Vega?», en Hacia la tragedia áurea: lecturas para un nuevo milenio, coords. F.A. de Armas, L. García Lorenzo y E. García Santo-Tomás, Iberoamericana-Vervuert, Madrid-Frankfurt am Main, 2008, pp. 287-299.

OlezA, Joan, «La propuesta teatral del primer Lope de Vega», Cuadernos de Filología. III. Literatura: análisis, 1-2 (1981), pp. 153-223.

OlezA, Joan, «Los géneros en el teatro de Lope de Vega: el rumor de las diferencias», en Del horror a la risa: los géneros dramáticos clásicos. Homenaje a Christiane Faliu-Lacourt, coords. I. Arellano Ayuso y V. García Ruiz, Reichenberger, Kassel, 1994, pp. 235-250. 